\title{
HUBUNGAN PERAN PERAWAT DALAM TIMBANG TERIMA DENGAN UPAYA MENGOPTIMALKAN KESELAMATAN PASIEN
}

\author{
Andi Mappanganro ${ }^{1}$, Vifta Ekariani ${ }^{2}$ \\ ${ }^{1}$ E-mail: andi_ns20@yahoo.com. \\ 1,2, ProgamStudi Ilmu Keperawatan FKM UMI
}

\begin{abstract}
ABSTRAK
Perawat mempunyai peranan penting untuk mendorong peningkatan keselamatan pasien, salah satunya adalah komunikasi yang baik antar sesama perawat pada saat pelaksanaan timbang terima. Kegagalan dalam melakukan komunikasi pada saat timbang terima dapat menimbulkan dampak yang serius terhadap pelayanan kesehatan. Penelitian ini bertujuan untuk mengetahui hubungan peran perawat dalam timbang terima dengan upaya mengoptimalkan keselamatan pasien diruang rawat inap bedah Rumah Sakit TK II Pelamonia.

Metodepenelitian yang digunakan dalam penelitian ini metodekuantitatif dengan pendekatan cross sectional study yaitu suatu studi mengukur variable dalam satu waktu sekaligus. Adapun penentuan sampel dilakukan dengan teknik Nonprobability Sampling dengan jenis Pursposive Sampling dengan besar sampel sebanyak 40 responden. Uji hubungan dengan menggunakan uji statistik dengan tingkat kemaknaan $\propto=0,05$.

Hasil penelitian menunjukkan, kategori baik mengenai peran perawat dalam timbang terimaada $85,0 \%$ perawat dan kategori kurang baikada15,0\% perawat. Sedangkan upaya mengoptimalkan keselamatan pasien, $82,5 \%$ perawat yang mengoptimalkan dan $17,5 \%$ perawat yang kurang mengoptimalkan. Hasil analisis menunjukkan bahwa ada hubungan peran perawat dalam timbang terima dengan upaya mengoptimalkan keselamatan pasien dengan nilai $\rho=0,005$.

Kesimpulan dari penelitian ini adalah ada hubungan peran perawat dalam timbang terima dengan upaya mengoptimalkan keselamatan pasien di ruang rawat inap Rumah Sakit TK II Pelamonia.
\end{abstract}

\section{KATA KUNCI: PeranPerawat, TimbangTerima, Keselamatan Pasien.}

\section{ABSTRACT}

Nurses have an important role to encourage improvement in patient safety, one of which is good communication between fellow nurses at the time of weighing. Failure to communicate when weighing can have a serious impact on health services. This study aims to determine the relationship between the role of nurses in weighing with efforts to optimize patient safety in inpatient surgery at TK II Pelamonia Hospital.

The research method used in this study is a quantitative method with a cross sectional study approach, which is a study that measures variables simultaneously. Determination of the sample is done using Nonprobability Sampling with Purposive Sampling with a sample size of 40 respondents. Relationship test using statistical tests with a significance level $\propto=0.05$.

The results showed that the good category regarding the role of nurses in weighing was $85.0 \%$ nurses and the unfavorable category was $15.0 \%$ nurses. While efforts to optimize patient safety, $82.5 \%$ of nurses optimize and $17.5 \%$ of nurses less optimize. The analysis shows that there is a relationship between the role of nurses in weighing with efforts to optimize patient safety with a value of $\rho=0.005$.

The conclusion of this study is that there is a relationship between the role of nurses in weighing with efforts to optimize patient safety in the inpatient room at TK II Pelamonia Hospital.

KEYWORDS: The Role of Nurses, Weighs, Patient Safety. 


\section{PENDAHULUAN}

World Health Organization (WHO)
menyatakan bahwa Keselamatan pasien
(Patien Safety) merupakan masalah
kesehatan global yang terjadi dalam
pelayanan kesehatan (WHO, 2013).
Keselamatan pasien (Patien Safety)

Safety) merupakan suatu komponen penting dalam memberikan asuhan keperawatan yang berkualitas, di karenakan pasien safety merupakan suatu langkah awal untuk menghindari kesalahan dalam pelayanan kesehatan.Oleh karena itu, keselamatan pasien (pasien safety) diartikan sebagai penghindaran, pencegahan, dan perbaikan dari kejadian yang tidak diharapkan (Triwibowo, 2016).

Sementara itu, kesalahan yang terjadi dalam pelayanan kesehatan sebagian besar disebabkan karena buruknya komunikasi dan pemahaman dalam tim pada saatmelakukan timbangterima (Kesrianti, 2014). Timbang terima adalah suatu teknik untuk menyampaikan sertamenerima suatu informasi yang berkaitan dengan kondisi pasien. Timbang terima harus dilakukan seefektif mungkin dengan menjelaskan secara singkat, jelas dan tentang tindakan mandiri perawat, tindakan kolaboratif, yang sudah lengkap dan belum dilakukan serta perkembangan pasien saat itu. Informasi yang disampaikan harus benar-benar akurat dan berkesinambungan sehingga asuhan keperawatan dapat berjalan dengan sempurna (Nursalam, 2016).

Dalam hal ini, perawatlah yang mempunyai peranan penting untuk medorong peningkatan komunikasi yang baik antar sesama perawat dan untuk meningkatkan keselamatan pasien sesuai yang dikemukakan oleh Kemenkes RI No 1691 Tahun 2011 tentang standar keselamatan pasien yaitu keselamatan pasien harus berkesinambungan dan komunikasi adalah kunci bagi staf untuk tercapainyakeselamatan pasien (Kemenkes, 2011).

Kegagalan dalam melakukan komunikasi pada saat pelaksanaan timbang terima dapat menimbulkan dampak yang serius yaitu kesalahan yang berkesinambungan dalam pelayanan keperawatan, pengobatan yang tidak tepat, kehilangan informasi, kesalahan tentang rencana keperawatan, kesalahan pada test penunjang, dan potensi kerugian bagi pasien, serta adanya ketidakpuasan pasien terhadap pelayanan keperawatan (Kesrianti, 2014).

Menurut Kamil (2011), Faktor yang mempengaruhi pelaksanaan timbang terima dalam pelayanan keperawatan diantaranya yaitu, faktor internal meliputi komunikasi, gangguan kelelahan, memori, pengetahuan dan pengalaman, dokumentasi. Faktor eksternal meliputi budaya organisasi, infrastruktur, keterbatasan teknologi dan tenaga kerja.

Berdasarkan penelitian yang dilakukan Kesrianti, pada tahun 2014 yang dilakukan di ruang rawat inap Rumah Sakit Universitas Hasanuddin menemukan bahwa pengetahuan, sikap, ketersediaan prosedur tetap, kepemimpinan, dan rekan kerja dapat mempengaruh terhadap pelaksanaan timbang terima yang dilakukan oleh perawat.

Penelitian yang dilakukan oleh Kurniawan, di Instalasi Rawat Inapa Rumah Sakit Ciamis Tahun 2018. Menyatakan bahwa sebagian besar perawat melaksanakan timbang terima sering berfokus pada hal-hal yang dianggap penting saja, seperti hanyamenyampaikan informasi terkait hasil anamnesa tanpa ada pemeriksaan lanjut. Pemeriksaan fisik dan pemeriksaan penunjang hanya disampaiakan terhadap pasien yang mengalami masalah yang cukup serius saja tanpa menyampaikan diagnosa keperawatannya.Sedangkan

informasi terkait tindakan yang sudah dilakukan, rekomendasi terhadap rencana tindakan lebih lanjut, serta klarifikasi materi operan yang telah disampaikan sering diabaikan dan dianggap tidak terlalu penting untuk perawat melaksanakannya. Kondisi ini dipengaruhi oleh berbagai hal, diantaranya adalah faktor efisiensi waktu karena dianggap terlalu lama dan mengulur waktu pada saat operan dinas, sehingga pada saat operan hanya hal-hal yang tertentu saja yang disampaikan.

Word Health Organization (WHO) tahun 2013 mencatat pelaporan kasus sebanyak 25.000 - 30.000terjadi kecacatan yang permanen pada pasien di Australia, 11\% disebakan karena kegagalan komunikasi (WHO,2013). Komite Keselamatan Pasien 
Rumah Sakit (KKP-RS) tahun 2012 mencatat laporan kasusu Di Indonesia didapatkan Kejadian Nyaris Cedera (KNC) yaitu mencapai 53,33\% sedangkan Kejadian Tidak Diharapkan (KTD) yaitu mencapai $46,67 \%$. Pada tahun 2012, ditemukan bahwa provinsi Jawa barat menempati urutan tertinggi yaitu $33.33 \%$ disusul provinsi lainnya Banten $20.0 \%$, Jawa Tengah 20.0\%, DKI jakarta $16.67 \%$, Bali $6.67 \%$. dan jawa Timur $3.33 \%$ (KKP-RS, 2012).

Berdasarkan dari hasil data awal yang telah didapatkan dari Rumah Sakit TK II Pelamonia diruang rawat inap bedah terdapat 40 perawat yang akan dijadikan responden dalam penelitian ini diantaranya diruang Anyelir sebanyak 14 orang, diruangan Mawar sebanya16 orang, dan diruang Tulip sebayak 10 orang. Dari hasil wawancara awal yang dilakukan pada beberapa perawat dimasing-masing ruangan, di ketahui bahwa setiap rawat inap mengadakan 2-3 kali timbang terima/operan setiap harinya. Dikatakan juga bahwa sering kaliperawat pelaksana pulang terlebih dahulu atau datang terlambat sehingga tidak mengikuti timbang terima yang berujung pada miss-communication antar perawat.

Penelitian ini bertujuan untuk mengetahui hubungan peran perawat dalam timbang terima dengan upaya mengoptimalkan keselamatan pasien di ruang rawat inap bedah Rumah Sakit TK II Pelamonia.

\section{Metode Penelitian}

Penelitian ini menggunakan metode kuantitatif dengan pendekatan cross sectional study yaitu suatu studi mengukur variable dalam satu waktu sekaligus (Sugiyono, 2013).Penelitian dilakukan dalam periode Maret - Juli 2019.

\section{Populasi dan Sampel}

Populasi dalam penelitian ini adalah perawat yang bertugas diruang rawat inap bedah Rumah Sakit TK II Pelamonia.Sampel penelitian dengan menggunakan rancangan Nonprobability Sampling dengan jenis Pursposive Sampling. Cara penetapan sampel dengan cara memilih sampel diantara populasi sesuai dengan yang dikehendaki peneliti, sehingga tersebut dapat mewakili
populasi.Sampel penelitian ini adalah perawat pelaksana diruang rawat inap bedah dengan besar sampel sebanyak 40 perawat.

\section{Hasil Penelitian}

\section{Karakteristik Responden}

Tabel 5.1

Distribusi Responden Berdasarkan Karakteristik di RS TK.II Pelamonia Makassar

\begin{tabular}{ccc}
\hline Karakteristik & \multicolumn{2}{c}{ Jumlah } \\
\cline { 2 - 3 } Umur & $\mathrm{n}$ & $\%$ \\
$\mathbf{1 7 - 2 5}$ & 3 & 7,5 \\
$\mathbf{2 6 - 3 5}$ & 31 & 77,5 \\
$36-45$ & 6 & 15,0 \\
Total & $\mathbf{4 0}$ & $\mathbf{1 0 0}$ \\
Jenis Kelamin & & \\
Laki-laki & 7 & 17,5 \\
Perempuan & 33 & 82,5 \\
$\quad$ Total & $\mathbf{4 0}$ & $\mathbf{1 0 0}$ \\
Pendidikan & & \\
Terakhir & & \\
Vokasional & 30 & 75,0 \\
(D3/S1) & & \\
Profesional (Ners) & 10 & 25,0 \\
Total & $\mathbf{4 0}$ & $\mathbf{1 0 0}$ \\
Lama Kerja & & \\
$\leq 1-5$ Tahun & 16 & 40,0 \\
$>$ 5 Tahun & 24 & 60,0 \\
Total & $\mathbf{4 0}$ & $\mathbf{1 0 0}$ \\
\hline
\end{tabular}

Sumber: data primer2019

Berdasarkan tabel 5.1 tentang distribusi responden menurut umur, jenis kelamin, pendidikan terakhir lama kerja di Rumah Sakit TK II Pelamonia Makassar menunjukkan bahwa jumlah responden tertinggi berada pada umur 26-35 tahun yaitu $31(77,5 \%)$ Untuk jenis kelamin jumlah responden tertinggi yaitu yang berjenis kelamin perempuan sebanyak 33 (82,5\%). Untuk Pendidikan Terakhir sebanyak30 orang $(75,0 \%)$ dalam kategori pendidikan vokasional (DIII dan S1). Dari jumlah 30 orang tersebut, sebanyak 9 perawat murni DIII dan sebanyak 21 orang dengan pendidkan S1 namun belum menyelessaikan pendidkan profesi ners. Sedangkan lama kerja didominasi dengan jumlah responden tertinggi yaitu > 5 tahun sebanyak 24 $(60,0 \%)$. 


\section{Analisis Univariat}

Analisis univariat (analisis presentase) yaitu analisis yang digunakan untuk mendapatkan gambaran distribusi responden serta menggambarkan variabel bebas dan variabel terikat.

Tabel 5.2

Distribusi Karakteristik Responden

BerdasarkanPeran Perawatdalam

Timbang Terima Di Ruang Rawat

Inap Bedah RumahSakit TK II Pelamonia

\begin{tabular}{ccc}
\hline Peran Perawat & \multicolumn{3}{c}{ Jumlah } \\
\cline { 2 - 3 } dalam Timbang & \multicolumn{3}{c}{$\mathrm{n}$} \\
Terima & \multicolumn{3}{c}{} \\
Baik & 34 & 85.0 \\
KurangBaik & 6 & 15.0 \\
Total & 40 & 100 \\
\hline
\end{tabular}

Sumber : Data Primer 2019

Berdasarkan tabel 5.2 diatas peran perawat dalam timbang terima diatas, menunjukkan bahwa dari 40 responden sebanyak 34 $(85,0 \%)$ yang memiliki peran yang baik dalam timbang terima. Sedangkan responden yang memiliki peran kurang baik dalam timbang terima sebanyak $6(15,0 \%)$.

Tabel 5.3

Distribusi Karakteristik Responden Berdasarkan Upaya Mengoptimalkan Keselamatan Pasien di Ruang Rawat Inap Bedah Rumah Sakit TK Pelamonia

\begin{tabular}{ccc}
\hline Mengoptimalkan & \multicolumn{2}{c}{ Jumlah } \\
\cline { 2 - 3 } Keselamatan & \multicolumn{2}{c}{$\mathrm{n}$} \\
Pasien & 33 & 82,5 \\
Mengoptimalkan & 7 & 17,5 \\
Kurang & 7 & \\
Mengoptimalkan & & 100 \\
Total & 40 & 100 \\
\hline
\end{tabular}

Sumber : Data Primer 2019

Berdasarkan tabel 5.3 diatas upaya mengoptimalkan keselamatan pasien diatas, menunjukkan bahwa dari 40 responden sebanyak $33(82,5 \%)$ yang mengoptimalkan keselamatan pasien. Sedangkan responden yang kurang mengoptimalkan keselamatan pasien sebanyak $7(17,5 \%)$

\section{Analisis Bivariat}

Melihat hubungan antara peran perawat dalam timbang terima dengan upaya mengoptimalkan keselamatan pasien di Rumah Sakit TK II Pelamonia.

Tabel 5.4

Peran Perawat dalam timbang Terima dengan Upaya Mengoptimalkan Keselamatan Pasien di Ruang Rawat Inap Bedah Rumah Sakit TK II Pelamonia

\begin{tabular}{|c|c|c|c|c|c|c|c|}
\hline \multirow{3}{*}{$\begin{array}{l}\text { Peran } \\
\text { Perawat } \\
\text { dalam } \\
\text { Timbang } \\
\text { Terima }\end{array}$} & \multicolumn{4}{|c|}{$\begin{array}{c}\text { Mengoptimalkan Keselamatan } \\
\text { Pasien }\end{array}$} & \multirow{2}{*}{\multicolumn{2}{|c|}{ Total }} & \multirow[t]{2}{*}{$\rho_{\text {Value }}^{\rho}$} \\
\hline & \multicolumn{2}{|c|}{ Mengoptimalkan } & \multicolumn{2}{|c|}{$\begin{array}{c}\text { Kurang } \\
\text { mengoptimalk } \\
\text { an }\end{array}$} & & & \\
\hline & $n$ & $\%$ & $n$ & $\%$ & $n$ & $\%$ & \\
\hline Baik & 31 & 91,2 & 3 & 8,8 & 34 & 100 & \\
\hline Kurang & 2 & 33,3 & 4 & 66,7 & 6 & 100 & 0,00 \\
\hline Total & 33 & 82,5 & 7 & 17,5 & 40 & 100 & \\
\hline
\end{tabular}

Sumber : Data Primer 2019

Tabel 5.4 menunjukkan bahwa perawat yang memilki peran baik dalam timbang terimadengan mengoptimalkan keselamatan pasien sebanyak 31 orang $(91,2 \%)$, dan perawat yang memiliki peran yang baik dalam timbang terima dan kurang mengoptimalkan keselamatan pasien sebanyak 3 orang $(8,8 \%)$. Sedangkan perawat yang memiliki peran yang kurang baik dalam timbang te rima dengan mengoptimalkan keselamatan pasien sebanyak 2 orang $(33,3 \%)$, dan perawat yang memiliki peran yang kurang baik dengan kurang mengoptimalkan keselamatan pasien sebanyak 4 orang $(66,7 \%)$.

Berdasarkan hasil uji statistik chisquare didapatkan nilai $\rho=0,005$ lebih kecil dari $\alpha=0,05$ hal ini menunjukkan bahwa ada hubungan bermakna peran perawat dalam timbang terima dengan upaya mengoptimalkan keselamatan pasien di ruang rawat inap bedah Rumah Sakit TK II Pelamonia. 
PEMBAHASAN

Peran Perawat dalam Timbang Terima.

Berdasarkan hasil penelitian yang dilakukan terhadap 40 perawat didapatkan bahwa ada sebanyak 34 perawat yang memiliki peran yang baik dalam pelaksanaan timbang terima dan ada sebanyak 6 perawat yang memiliki peran kurang dalam pelaksanaan timbang terima .

Hasil uji satatistik chisquarediperoleh nila $\rho=0,005<\alpha=0,005$. Hal ini menunjukkan bahwa ada hubungan yang bermakna antara peran perawat dalam timbang terima denganupaya mengoptimalkan keselamatan pasien.

Penelitian ini sejalan dengan penelitian yang dilakukan oleh Manopo (2013) Tentang Hubungan Antara Penerapan Timbang Terima Pasien dengan Perawat Pelaksana di RSU GMIM Kolaboran Amorang dimana didapatkan nilai $\rho=0,000<0,05$ hal ini menunjukan bahwa ada hubungan antara penerapan timbang terima pasien dengan keselamatan pasien.

Timbang terima adalah teknik untuk menyampaikan dan menerima suatu informasi yang berkaitan dengan keadaan pasien. Timbang terima harus dilakukan seefektif mungkin dengan menjelaskan secara singkat, jelas dan lengkap tentang tindakan mandiri perawat, tindakan kolaboratif yang sudah dan belum dilakukan serta perkembangan pasien pada saat itu. Informasi yang disampaiakan harus akurat sehingga kesinambungan asuhan keperawatan dapat berjalan dengan sempurna (Nursalam, 2016).

\section{Upaya Perawat Mengoptimalkan Keselamatan Pasien}

Dalam keselamatan pasien terdapat 6 goals diantaranya identifikasi pasien, komunikasi efektif, peningkatan keamanan obat, peningkatan benar (lokasi, pasien, prosedur pembedahan), mengurangi resiko infeksi, serta pengurangan resiko jatuh.Penelitian ini menfokuskan pada tindakan keselamatan pasien di ruang perawatan yang berhubungan langsung dengan tindakan perawat salah satunya adalah penekanan perihal keselamatan pasien saat timbang terima.
Berdasarkan hasil penelitian ini didapatkan bahwa dari 40 perawat yang mengoptimalkan keselamatan pasien sebanyak 33 perawat dan yang kurang mengoptimalkan keselamatan pasien sebanyak 7 perawat.

Hasil uji satatistik chi-squar diperoleh nila $\rho=0,005<\alpha=0,005$. Hal ini menunjukkan bahwa ada hubungan yang bermakna antara peran perawat dalam timbang terima dengan upaya mengoptimalkan keselamatan pasien di Ruang Rawat Inap Rumah sakit TK II Pelamonia.

Hal ini sejalan dengan penelitian yang dilakukan oleh Windyastuti (2018) tentang Hubungan Pelaksanaan Timbang Terima Dengan Keselamatan Pasien di Ruang Rawat Inap Kelas III RSI Agung Semarang didapatkan nilai $\rho=0,000<0,05$ menunjukan bahwa ada hubungan pelaksanaan timbang terima dengan upaya mengoptimalkan keselamatan pasien.

Hubungan Peran Perawat dalam Timbang Terima dengan Upaya Mengoptimalkan Keselamatan Pasien.

Berdasarkan hasil penelitian yang dilakukan pada 40 perawat pelaksana di ruang rawat inap Rumah Sakit TK. II Pelamonia didapatkan $34(85,5 \%)$ perawat yang memiliki peran yang baik dan hanya 6 $(15,0 \%)$ perawat dalam kategori kurang dalam timbang terima. Dari jumlah 34 perawat tersebut, terdapat $31 \quad(92,0 \%)$ perawat yang mengoptimalkan keselamatan pasien. Hal iniberarti bahwa peran perawat yang baik dalam timbang terima akan mengoptimalkan keselamatan pasien.

Dalam penelitian ini juga didapatkan masih ada perawat yang tidak melaksanakan Standar Oprational Procedur (SOP) didapatkan 2 orang perawat yang dinas untuk shift berikutnya melakukan tindakan keperawatan pada pasien sebelum pergantian shift atau sebelum dilaksanakannya timbang terima, masihada 4 orang perawat yang didapatkan tidak mecuci tangan dengan benar.

Seorang harus bekerja sesuai SOP termasuk SOP cuci tangan, jangan sampai kita termasuk dalam golongan yang disebutkan dalam Al Quran dalam surah Al 
A'raf (82) yang terjemahnya :Sesungguhnya mereka adalah orang-orang yang berpurapura mensucikan diri. Dengan tidak mengikuti SOP cuci tangan dengan benar mengindikasikan kita tidak serius atau pun berpura pura mensucikan diri sebelum atau setelah kita bekerja.

Sedangkan $(8,8 \%)$ perawat yang memiliki peran yang baik dalam timbang terima tetapi kurang mengoptimalkan keselamatan pasien hal itu dapat disebabkan karena berbagai macam hal, jika dilihat dari karakteristik perawat yang memliki peran yang baik dalam timbang terima tetapi mengoptimalkan keselamatan pasien merupakan perawat dengan masa kerja $\leq 5$ tahun dan berpendidikan D3 sehingga hal ini kemungkinan besar penyebabnya yaitu masa kerja dan latar belakang pendidikan perawat.

Hal ini sejalan dengan penelitian yang dilakukan oleh Setyani (2016) yang berjudul Implementasi Sasaran Keselamatan Pasien di Runang Rawat Inap RSU Kabupaten Tangerang dengan hasil penelitian yang menyatakan bahwa ada hubungan lama kerja dengan implementasi sasaran keselamatan pasien berdasarkan hasil tersebut didapatkan nilai $\rho=0,008$. Namun penelitianiniberbeda dengan hasil penelitian yang dilakukan oleh Dewi (2012) yang mengatakan bahwa tidak ada hubungan lama kerja dengan pelaksanaan timbang terima $\rho=$ $0,626(\rho \geq 0,005)$ dan penerapan keselamatan pasien $\rho=0,972(\rho \geq 0,005)$.

Hasil penelitian ini juga menunjukkan bahwa pendidikan perawat yang memilki peran yang baik dalam timbang terima tetapi kurang mengoptimalkan keselamatan pasien yaitu perawat yang berlatar belakang pendidikan D3.Hal ini berarti bahwa semakin tinggi pendidikan seseorang akan berpengaruh terhadap pelaksanaan tugasnya dimana semakin tinggi pengetahuan seseorang maka semakin baik dalam melaksanakan tindakan untuk meningkatkan keselamatan pasien. Pengetahuan merupakan faktor penting untuk membantu seseorang dalam mengambil keputusan, tetapi tidak selamanya pengetahuan bisa menghindari perawat dari kejadian yang tidak diinginkan, misalnya perawat yang memiliki pengetahuan yang baik tidak selamanya akan melaksanakan keselamatan pasien dengan baik dikarenakan segala tindakan yang dilakukan beresiko untuk terjadi kesalahan. Pengetahuan merupakan hal yang sangat penting untuk terbentuknya suatu prilaku seseorang dimana prilaku yang terbentuk, akan didasari oleh pengetahuan sehingga bersifat lebih baik dibandingkan prilaku yang tidak didasari dengan pengetahuan (Notoadmodjo, 2011).

Begitupun menurut penelitian Bawelle (2013) yang berjudul Hubungan Pengetahuan dan Sikap Perawat dengan Pelaksanaan Keselamatan Pasien (Patient Safety) di Ruang Rawat Inap RSUD Liun Kendage Tahuna yang menyatakan bahwa semakin tinggi pengetahuan seseorang semakin baik dalam pelaksanaan keselamatan pasien.

Hal ini sejalan dengan penelitian yang dilakukan oleh Oktaviani (2015) dengan judul hubungan pengetahuan dengan kepatuhan perawat dalam pelaksanaan Standar Prosedur Operasional Pencegahan Resiko Jatuh Pasien di Rumah Sakit Panti Waluyo Surakarta menyatakan bahwa terdapat hubungan yang signifikan antara pengetahuan dengan kepatuhan perawat dalam pelaksanaan SOP pencegahan resiko jatuh di Rumah Sakit Panti Waluyo.

Namun berbeda dengan hasil penelitian yang dilakukan oleh Pogala (2017) yang menyatakan bahwa tidak ada hubungan yang signifikan antara tingkat pendidikan perawat dengan kepatuhan perawat dalam melaksanakan SOP resiko pasien jatuh di Rumah Sakit X Kendari. dengan nilai $\rho=$ 1,000 .

Hasil lain yang didapatkan dalam penelitian ini adalah karaktertik umur. Perawat yang memilki peran yang baik danmampu mengoptimalkan keselamatan pasien,jika dibandingkan dengan perawat yang kurang baik dalam timbang terima dan kurang mengoptimalkan keselamatan pasien ternyata dominan pada umur rata-rata 26-35 tahun. Hal ini menggambarkan bahwa pada penelitian ini umur seseorang tidak berpengaruh terhadap kinerja perawat, meskipun pada usia tersebut termasuk dalam usia produktif dimana dengan usia tersebut seharusnya perawat mampu melakukan pekerjaannya dengan baik. Menurut Depkes (2015) usia 26-35 tahun merupakan usia yang 
memiliki motivasi untuk berkerja dan menghasilkan sesuatu.

Penelitian ini tidak sejalan dengan Nitisemito dalam (Kirana 2016), yang menyatakan bahwa usia lebih muda umumnya kurang memiliki sikap disiplin dalam bekerja dibandingkan dengan usia yang lebih tua. Begitu pun penelitian yang dilakukan oleh Worung (2014) juga tidak sejalan dengan penelitian ini yang menyatakan bahwa terdapat hubungan antara umur dan kinerja perawat dengan nilai $\rho=$ 0,00 .

Hasil lain yang didapatkan peneliti berdasarkan observasi yang dilakukan diruangan rawat inap bedah Rumah Sakit TK II Pelamonia didapatkan bahwa kepala ruangan masih kurang memperhatikan atau kurang mengevaluasi pelaksanaan kegiatan timbang terima.Hal ini tentunya harus menjadi perhatian khusus karena dapat berpengaruh terhadap pelayanan kesehatan yang akan diberikan.

Hal ini didukung oleh penelitian yang dilakukan oleh Mandagi (2015) menyatakan bahwa ada hubungan antara supervisi pimpinan dengan kinerja perawat dalam menerapkan asuhan keperawatan di Rumah Sakit Bethesda GMIM Tomohon dengan nilai $\rho=0,019$. Meskipun hasil penelitian ini tidak sejalan penelitian Anggeria (2018) yang menyatakan bahwa tidak ada hubungan antara supervisi dengan pelaksanaan asuhan keperawatan di Ruang Rawat Inap Lantai 10 Rumah Sakit Umum Roya.

Selain itu, hasil penelitian inijuga sejalan dengan penelitian yang dilakukan oleh Triwibowo, Sulhah, \& Nur (2016) yang menyatakan bahwa terdapat hubungan yang signifikan antara pelaksanaan handover dengan patient safety.Baik buruknya handover ditunjang dengan adanya pateint Safety.

\section{KESIMPULAN DAN SARAN \\ Kesimpulan}

Adapun kesimpulan penelitian ini sebagai berikut :

Peran perawat dalam timbang terima di Ruang Rawat Inap Bedah Rumah Sakit TK II Pelamonia dalam kategori baik sebanyak $85,0 \%$ dan yang kurang sebanyak $15,0 \%$.

Terdapat $82,5 \%$ perawat yang mengupayakan mengoptimalkan dan sebanyak $17,5 \%$ perawat tidak mengupayakan mengoptimalkan. keselamatan pasien di Ruang Rawat Inap Bedah Rumah Sakit TK II Pelamonia

Ada hubungan peran perawat dalam timbang terima dengan upaya mengoptimalkan keselamatan pasien di Ruang Rawat Inap Bedah Rumah Sakit TK II Pelamonia Kota Makassar dengan hasil uji satatistik chi-square $\rho=0,005$.

\section{Saran}

Saran yang diberikan terkait dengan penelitian ini adalah

Bagi Perawat

Sebagai pemberi pelayanan keperawatan, perawat kiranya lebih mematuhi Standar Oprational Procedur (SOP) yang telah ditetapkan, meningkatkan kerjasama dengan tim, dan mendokumentasikan semua asuhan keperawatan yang diberikan kepada pasien dan keluarga.

\section{Bagi institusi}

Pelayanan kesehatan Diharapkan lebih meningkatkanupaya keselamatan pasien di Rumah Sakit, meningkatkan kegiatan supervise kepala ruangan di ruang rawat khususnya mengevaluasi program keselamatan pasien.Selain itu diharapkan dukungan institusi kepada perawat untuk melanjutkan pendidikan dan pemberian pelatihan secara berkesinambungan.

\section{DAFTAR PUSTAKA}

Agreria, E. (2018). Hubungan Supervisi dengan Pelaksanaan Asuhan Keperawatan di Ruang Rawat Inap Lantai $10 \quad R S U$ Royal Prima Medan. Jurnal Jumatik, Vol 3 (2) 78-97.

Bawelle, S. (2013). Hubungan Pengetahuan dan Sikap Perawat dengan Pelaksanaan Keselamatan Pasien 
(Patient safety) di Ruang Rawat Inap RSUD Liun Kondage Tahuna. Journal Keperawatan (e.Kp), Vol 1 (1) 884-894).

Depkes RI. (2015).Tentang Profil Kesehatan Indonesia.JakartaKementrian Kesehatan RI.

DepartemenAgama RI. (2015). Al Quran danterjemhnya.

Goraph, M. (2018). Hubungan Timbang Terima (Operan Shift) dengan Kinerja Perawat Pelaksana Diruang Rawat Inap Bangsal RSU GMIM Pancaran Kasih Manado.ejournal Keprawatan, vol 6(1), 1-5

Komite Keselamatan Pasien Rumah Sakit. (2012). Pedoman pelaporan insiden keselamatan pasien (IKP), Komite Keselamatan Pasien RumaSakit. Jakarta

Kamil, H. (2011). Handover Dalam Pelayanan Keperawatan Handover In Nursing Care. Idea Nursing Journal, 4(2), 144-152.

Kemenkes RI. (2011). Permenkes RI No. 1691/Menkes/VII/2011 tentang Keselamatan Pasien Rumah Sakit.

Kesrianti, A. M. (2014). Faktor-faktor yang mempengaruhi komunikasi pada Saat handover di ruang rawat inap Rumah Sakit Universitas Hasanuddin. Jurnal Ilmiah, 1314.

Kirana, D. (2016).Hubungan sikap disiplin perawat dengan efektivitas pelaksanaan timbang terima di RSUD dr. Abdoer Rahim Situebondo. (Tesis, Universitas Jember).

Manopo, Q. (2013). Hubungan Antara Penerapan Timbang Terima Pasien dengan Keselamatan Pasien Oleh Perawat Pelaksana di RSU GMIM Kalooran Amurang. , vol 6(1), 1-5.

Mandagi, F. (2013). Analisis Faktor-Faktor yang Berhubungan dengan Kinerja Perawat dalam Menerapkan Asuhan Keperawatan di Rumah Sakit Umum Bethesda GIMIM Tomohon. Journal e-Biomedi, Vol 2 (3) 885-894.

Nursalam. (2016). Manajement keperawatan aplikasi dalam praktik keperawataan aplikasi dalam prakti keperawatan profesional. (ed 4).Jakarta: Selemba Medika.

Notoadmodjo, N. (2011). Kesehatan Masyarakat Ilmu dan Seni (Edisi Revisi) Jakarta Rineka Cipta

Oktaviani, A. (2015).Hubungan Pengetahuan dengan Kepatuhan Perawat dalam Pelaksanaan Standar Prosedur Operasional Pencegahan Resiko Jatuh Pasien di Rumah Sakit Panti Waluyo Surakarta. $l 2$ (3) 885-894.

Pagala, I. (2017). Prilaku Kepatuhan Perawat Melaksanakan SOP Terhadap kejadian Keselamatan Pasien di Rumah Sakit X Kendari. Jurnal Promosi Kesehatan Indonesia, Vol 12 (1) 139-149198.

Setyani. M.(2016). Implementasi Sasaran Keselamatan Pasien di Ruang Rawat Inap Rumah Sakit Kabupaten Tangerang.Journal JKFTVol 2, No 2 (2016).

Soepradjo, R. (2016).Hubungan antara Jenis Kelamin dan Motivasi Kerja dengan Kinerja Perawat di Rumah Sakit Jiwa Prof. Dr. V. L. Ratumbuysang Provinsi Sulawesi Utara.Diakses dari website http//:ejournal.unstrat.ac.id/.Dia kses tanggal 10 Juli2019. 
Sugiyono. (2013). Metode Penelitian Manajemen: Pendekatan Kuantitatif, Kualitati, Kombinasi (Mixed Methods, Penelitian Tindakan (Action Research), Dan Penelitian Evaluasi. Bandung: Alfabeta

Trwibowo, C., Sulhah., Nur (2016). Handover Sebagai Upaya Peningkatan Keselamatan Pasien (Patient safety). Keperawatan Soederman. Vol 11(2).76-80.

Triwibowo, R. (2016). Studi Kualiatif peran handover dalam meningkatkan keselamatan pasien. Pena Medi ka, Vol.6 No 2. .Diakses dari website

World Health Organization. (2013) Pasien Sefety.

Wirawan, A. (2016). Pengaruh Tingkat Pendidkan dan Pengalaman Kerja Terhadap Kinerja Karyawan. vol 4 (1) 135-140 Diakses dari websitehttp.//ejournal.undiksha, ac.ad.pada tanggal 6 Agustus 2019.

Windyastuti, W. (2018). Hubungan Pelaksanaan Timbang Terima dengan Keselamatan Pasien Diruang Rawat Inap Kelas III RSI

Sultan Agung Semarang. Jurnal Keperawatan, Vol.5(2).132138.

Worung, P. (2014). Hubungan Umur Status Perkawinan dan Motivasi Kerja dengan Kinerja Praktik Keperawatan Jiwa di Rumah Sakit Jiwa Prof. Dr. V. L. Ratumuysang Provinsi Sulwasi Utara. 